\title{
Methodologic Innovations and Advances in Social Epidemiology
}

\author{
J. Michael Oakes • Kate N. Andrade
}

Published online: 17 January 2014

(C) Springer International Publishing AG 2014

\begin{abstract}
This paper reviews recent innovations and advances in social epidemiological methodology. We rely on the only social epidemiological text focused on research methods, a literature review from leading epidemiologic journals, and other influential sources. Results show that social epidemiologic methodology is robust and improving. Advances have been made in understanding causal effects, effect identification, multilevel thinking, and meaningful research. Substantial improvements have been made in our understanding and measurement of race and socioeconomic status. Obvious shortcomings remain in our understanding of simultaneity and reciprocal causation, macro-micro transitions, appreciation of culture, and the use of case studies. The subdiscipline's utility would increase if practitioners paid closer attention to methodological insights and advances.
\end{abstract}

Keywords Innovations $\cdot$ Social epidemiology Methodology · Causal effects · Effect identification · Multilevel thinking $\cdot$ Meaningful research $\cdot$ Simultaneity · Reciprocal causation $\cdot$ Macro-micro transitions

\section{Introduction}

Summarizing methodological innovations and advances in social epidemiology is a daunting challenge. A proper summary should both recognize important innovations and illuminate gaps in the methodological landscape. Yet, we have an additional problem caused by the fuzzy boundaries of social epidemiology itself [1-3]. Just what is social epidemiology? Should a review be limited to research conducted by self-

J. M. Oakes $(\bowtie) \cdot$ K. N. Andrade

Division of Epidemiology, University of Minnesota,

1300 South 2nd St, Suite 300, Minneapolis, MN 55454, USA

e-mail: oakes007@umn.edu identified social epidemiologists? What about limiting advances to those working in departments of epidemiology? What about contributions from sociology and/or economics? We found it impossible to identify any bright line for deciding what research to include in this summary. Accordingly, although we tried to be inclusive, we concede that this review is somewhat selective and conforms to our view of the subdiscipline.

What follows is based on the only text, thus far, that focuses on methods in social epidemiology, Methods in Social Epidemiology [4]. The second edition is currently being edited by this paper's first author, so the following review incorporates updates and changes not yet found in the peerreviewed literature. Additionally, we reviewed the social epidemiologic literature as found in leading epidemiology journals, including Social Science and Medicine.

We organize this review into four substantive subsections. The first addresses broad trends. The second addresses innovations in research designs and related ideas. The third section focuses on advances in measurement. The final section addresses emergent topics and approaches. A summative conclusion follows. We provide abundant citations throughout for those interested in further exploration. As it is a review, this article does not contain any studies with human or animal subjects performed by any of the authors.

\section{Broad Trends}

Social epidemiologists are becoming more methodologically sophisticated. During the past ten years there has been an increased focus on causal inference, an explosion in multilevel thinking, a shift towards policy-relevant research questions, and a refinement in our understanding of health disparities research. All of this bodes well for more meaningful substantive contributions. 
In our opinion, the most important methodological advancement in the past ten years is the attention that methodologists are paying to causality $[5-10,11 \bullet]$. The discipline is undergoing a methodological revolution focused on causal inference and meaningful, if not practicable, results. Merely documenting still more correlations between social factors and disease states no longer seems acceptable.

A modern approach to causation has been thoroughly articulated $[12,13]$. Briefly, most want to know what would happen to some health outcome, $\mathrm{Y}$, if persons were treated with (or exposed to) some social intervention, $\mathrm{X}$. This is a causal question and its evaluation rests on the idea of a counterfactual [14]. While it may be impossible to ever prove that $\mathrm{X}$ causes $\mathrm{Y}$, work done toward this end tends to yield more useful results.

A key component of causal inference is effect identification. In the simplest terms, identification means that one and only one effect (or model) explains the data, even as sample size approaches infinity [15]. Borrowing from Oakes [16], imagine a Martian observing a man who is looking at a mirror and moving his head. Assume that the Martian has no information about optics or human behavior. Given the data, the Martian would not know whether the head was causing the image to move or whether the image was causing the head to move. The observed data is not causally informative because the effects are not identified: both models explain the data. Identification has nothing to do with statistical inference, per se. Sampling distributions, confidence intervals, $\mathrm{p}$-values, and hypothesis tests are irrelevant because the sample size is assumed to be infinitely large. While empirical research requires both identification and statistical estimation, identification precedes estimation. Critically, collecting more of the same type of data will not solve fundamental identification problems. Instead of fussing about $\mathrm{p}$-values, influential social epidemiologists are now discussing identification strategies [11•].

One approach to identification is to imagine the ideal experiment for answering a hypothesis, even if it is a practical impossibility [15]. This thought exercise illuminates the differences between the ideal yet hypothetical data and the data at hand. Such differences represent the methodological assumptions necessary to infer that $\mathrm{X}$ causes $\mathrm{Y}$. If the assumptions are untenable or heroic, identification may be suspect and the utility of the research questioned. Furthermore, issues related to the difficulty of randomizing some treatments, such as race or sex, are often revealed.

In our opinion, the second most important methodological advancement has been the explosion in multilevel thinking and analysis [17-19]. The basic idea is that social contexts - which are necessarily at a higher or aggregate level — impact individual health outcomes. The mechanism may be direct, or it may be mediated through, say, health behaviors or even genes.

The term explosion is not an overstatement. In an admittedly crude analysis of epidemiologic and public health journal citations recorded in the PubMed database, we discovered that approximately 800 papers have used the term multilevel or multi-level in their titles or abstracts since 2003. The impact of such work is difficult to discern. Fortunately, a deeper, more nuanced understanding of the relationship between individuals and social contexts has begun to emerge. The challenge is the dynamic nature of this system, where individuals continually influence the social context around them and in turn, the social context influences the individuals living within [3]. These micro-to-macro and the macro-tomicro transitions are key to multilevel thinking and research [19]. Progress is apparent, but more is needed.

The third important methodologic trend is that social epidemiologists are increasingly focused on applied, policyrelated, or consequential research. Berk and Rossi [20] used the term policy space to describe treatments/interventions that were remotely possible in our current culture and/or sociopolitical system. They aimed to steer researchers away from investigating the effects of, say, eliminating racism or making the poor as wealthy as the rich. Technically, such interventions violate the 'closest possible world' assumption of counterfactual thinking [21]. Policy space anticipates the recent suggestions of Galea [22] about consequentialist epidemiology, and Lynch et al.'s [23] consideration of the practicality of early childhood interventions for better health.

Finally, we believe important strides have been made in the study of health disparities. Health disparities are inextricably linked to social epidemiology [24]. If morbidity and mortality were merely a function of genetics and immutable environmental exposures, social epidemiologists would have little to say or do about disparate outcomes. But this is not the case. Goods and burdens have always been allocated such that some benefit while others suffer. It is actually surprising that observed disparities are not greater given the brutality of some (historical) regimes. The core challenge is the tension between agency and structure, as thoughtfully articulated by Frohlich and Potvin [25]. Ultimately, we agree with Kaufman and Harper [26•] that health disparities research requires rigorous methodology.

\section{Research Designs}

In the past decade, social epidemiologists have made advances in understanding and exploiting better research designs, and aspects of the same. We maintain that the canonical design for social epidemiology is the group randomized trial because it incorporates social interaction and manipulates something (e.g., a policy) in order to observe potential outcomes. Hannan [27] offers a superb introduction. Wagenaar et al.'s [28] effort to experimentally induce community member interaction so as to reduce alcohol abuse is noteworthy. Relatedly, Biglan et al. [29] explain how to incorporate 
aspects of interrupted time series and community trial designs to assess the impact of state policy changes. Data requirements for this approach are high, but the inferential potential is compelling.

The idea of structural confounding is a more subtle innovation. Although not a new concept, the term was coined in 2006 by Oakes [30]. The idea is that some imagined or modeled intervention (e.g., moving poor persons to wealthy neighborhoods) represents a positivity violation; thus, offsupport inferences tend to conflict with observed data. Oakes and Johnson illuminate the issue through propensity score matching [31]; Messer et al. [32, 33] do the same with tabular methods. Oakes et al. [34] demonstrated how matched sampling can mitigate structural confounding in an otherwise conventional neighborhood effects study. Importantly, Leal et al. [35] found the problem to be severe in French urban areas, though, incredibly, effect estimates were similar when the problem was ignored. Ahern et al. [36] explained how to navigate structural confounding when studying collective efficacy. The work of Ho et al. [37] merits more attention because they describe how to pre-process data such that observations of interest are, save for a treatment/exposure, exchangeable.

Finally, social epidemiologists are increasingly exploiting natural experiments. Among notable efforts are Cerda et al.'s [38] assessment of how sociostructural change impacts on violence, Bruckner et al.'s [39] examination of cash lottery effects on Native American health, and Branas et al.'s [40] assessment of the influence of urban spaces on health. A related approach is to employ instrumental variable methods, which can be thought of as inducing natural experiments. Glymour's [41] review is both precise and accessible. Glymour et al. [42•] address the difficult to verify, subtle assumptions necessary for these models to yield unbiased effect estimates.

\section{Measurement}

The exposure of primary interest to social epidemiologists is the social system, which includes laws and policies, social movements and collective actions, conventions and norms, socialization, individual behaviors, and choices. The number of measures one might derive from the broad concept of the social system seems unlimited. More inquiry into the measurement of culture, religiosity, ideology, life goals, social control, and so forth is needed. Fortunately, some progress has been made in the measurement of traditionally evaluated aspects of the social system.

Social Capital/Social Support/Collective Efficacy. Social epidemiologists have made strides in measuring and analyzing social capital, social support, and collective efficacy. Among notable efforts are Ahern and Galea's [36] measurement of neighborhood collective efficacy using a scale developed by Sampson et al [43]. Muennig et al. [44] examined five forms of structural social capital and found mixed effects on health outcomes. Importantly, Girodano et al. [45] addressed causal inference in their study of social capital and self-rated health. In the opposite direction, Fletcher [46] examined intimate partner violence and health.

Race and Ethnicity. Race and ethnicity have long and complicated measurement histories. Both entail membership in a social group, as defined by the members themselves, an external group, or both [47]. Race, though, may best be appreciated as a construct for creating and reinforcing power structures. Though it was not always the case, social epidemiologists now realize that "race" should be understood as an ethnicity, where a group of individuals is linked together by a shared culture; it is rarely meaningful biologically $[48,49]$. Rather, the mechanisms that give rise to health differences by race likely include residential segregation, and both interpersonal and institutional discrimination. Evidence of progress includes Lewis et al. [50], who conducted a psychometric evaluation of a popular measure of discrimination and urged caution. Messer and Kaufman [51] clarified the issue of weathering and adverse birth outcomes. Das [52] considered how 'race' gets under the skin and inhibits health. Ford [53] advanced the idea of Public Health Critical Race praxis. And Ford and Harawa [54] thoughtfully addressed the conceptualization and measurement of ethnicity.

Socioeconomic Status/Position. Socioeconomic status (SES) is a central measure in social epidemiology, but its use is complicated by the fact that scholars have not agreed on a definition, and probably never will. We maintain that SES reflects one's access to collectively desired resources, be they material goods, money, power, friendship networks, healthcare, leisure time, or educational opportunities [55]. To varying degrees, SES has been related to health outcomes for as long as social groups have existed, with higher status increasing one's chance for a long and healthy life. In a noteworthy "advance", Oakes [56॰] argues that because of its imprecision, inactionable nature, and misuse, scientists should stop using the SES construct altogether. Instead, he suggests we rely on univariate measures, such as educational attainment or annual household income. Other advances include: Hajat et al. [57], who examine the effects of wealth on mortality and self-rated health in the USA; Nieto [58], who addresses the pathophysiology of poverty; Howe et al. [59], who consider measuring SES in low- and middle-income countries; Subramanian et al. [60], who recommend caution when examining the SES and CVD risk relationship in India; and Chen et al. [61], who reveal why repeated cross-sectional analysis of associations of SES can produce misleading results. 
Inequality. Several important social epidemiologic hypotheses revolve around the effect of social inequality on health. Harper and Lynch [62] provide an excellent summary of inequality measures. Krieger's [63] edited text on how inequality translates into health disparities remains relevant.

Segregation. Reardon [64] offers an excellent introduction to various measures of segregation. Innovative applications include Osypuk et al.'s [65] study of the differential effects of neighborhood segregation on Mexican immigrants, Hearst et al.'s [66] study of black-white segregation and infant mortality; and Kershaw et al.'s [67] examination of residential segregation and cardiovascular disease risks.

\section{Emergent Topics \& Approaches}

In this section, we aim to draw attention to emergent methodological innovations and advances. What follows is a brief summary of ideas we find noteworthy because they illuminate the dynamic nature of the relationship between societies and the individuals living within.

Social Network Analyses. Although Christakis and Fowler [68] famously examined the contagion of obesity and related outcomes, there are questions about the identification of such effects. Valente [69] offers a useful review of the issues. Advances include Doherty et al.'s [70] examination of social networks in syphilis outbreaks, and Fujimoto and Valente's [71] innovative investigation of causal social network influences on adolescent substance use. The potential utility of social network analyses could be great, but actual impacts on population health as a result of the research remain to be seen.

Systems Theory and Dynamic Modeling. A growing and vital area of social epidemiologic methodology is that of systems theory and dynamic modeling. Homer and Hirsch offer an accessible summary [72]. Building on seminal work by Koopman and Lynch [73], other advances include El-Sayed et al.'s [74] simulation to assess anti-obesity interventions, Galea et al.'s [75] consideration of causal effects and complex systems, Auchincloss and Diez-Roux's [76] approach to agent-based models, Yang et al.'s [77] spatially-enhanced, agent-based model to simulate people's walking behaviors within a city, and Diez-Roux's [78] thoughts on complex systems and health disparities. Gatrell [79] offers some cautionary notes and insightfully asks about the practicability of such investigations.

Life Course. Life course analysis is replete with identification problems, yet the ideas remain a foundation of social epidemiology. Bengtsson et al. [80] offers a helpful summary of the issues. Bastide-van Gemer et al. [81] advance life-course methods by linking them to now conventional concepts of causal inference. Davey Smith [82] traces early methods of life course analysis, and asks how far back intergenerational research should go [83]. This is an area ripe for methodological inquiry and advancement.

Neighborhood Effects. The independent effect of neighborhoods on health has been a central question for social epidemiology [84]. After a flurry of papers relying on mixed-model regression, Oakes [85] questioned our ability to identify neighborhood effects in observational designs. Vanderweele [86] clarified many of the assumptions necessary for identification. Beyond the insights into structural confounding described above, other advances include Schaefer-McDaniel et al.'s [87] use of systematic social observation. Additionally, several studies by Chaix and colleagues $[88,89]$ examine the aspects of confounding and participation in neighborhood data.

It seems that the most recent work is pushing investigators away from the notion of neighborhoods as the central social epidemiological unit of analysis, instead focusing on families. In their quasi-experimental study, Sariaslan et al. [90] found negligible impacts of neighborhoods on criminality, and suggested that social epidemiologists turn their attention to families. Although he disagreed with their empirical results, Oakes [91] agreed that it is time to move past neighborhoods and examine the influence of family structures. Additionally, Merlo et al. [92] found that families appear to play an important role in health outcomes. Votruba and Kling [93] examined the effects of neighborhood characteristics on the mortality of black male youth from the important Gautreaux study, yet found that human capital measures were more important than neighborhood deprivation measures. The torrent of multilevel studies purporting to reveal independent effects of neighborhoods on health outcomes appears to be subsiding.

Mediation/Decomposition. Understanding how some exposure, $\mathrm{X}$, causes some change in an outcome, $\mathrm{Y}$, is central to scientific explanation. After seminal work by Robins and Greenland [94], social epidemiologists have advanced this important, but difficult area. Influential work includes Kaufman et al. [95], who clarified what biological mediation is not, and Vanderweele [96], who described identification conditions for controlled direct effects, and natural direct and indirect effects. More recently, Nandi et al. [97] assessed the effect of childhood SES, as mediated by adult SES, on laterlife health. Overall, the primary contribution is that the approach to mediation famously advanced by Baron and Kenny [98] entails assumptions that are often indefensible in a social epidemiologic investigation.

Genetics. In the current era of genomics, if not genetic fetishism, social epidemiologists are in a unique position to 
contribute to our understanding of the interplay between genetics and the social environment. Freese [99] offers an excellent introduction to genetics for social scientists. Rehkopf and Adler [100] remind us that socioeconomic structures may be more important that genes. Toyokawa et al. [101] review how social conditions affect psychological health, and the epigenetic process. Strikingly, Godfredson [102] challenges social epidemiologists to show that inherited intelligence (i.e., IQ or $\mathrm{G}$ ) is not the fundamental cause of health disparities.

\section{Conclusions}

The state of social epidemiologic methodology is robust and improving. Methodologists continue to illuminate assumptions and offer new tools for addressing important questions. Nevertheless, several gaps remain. Among them is the slippery issue of simultaneity and reciprocal causation. VanderWeele et al. [103] have made some progress on this problem, but more attention is needed. Perhaps recent work [104] on coevolution will help. Less technically, but no less important, is a paper by Glass [105], who reminds us that "culture" remains overlooked and understudied. Our take is that carefully conducted case studies are woefully lacking in the literature. We believe work such as Elster's overlooked Local Justice project [106] would improve our understanding of the ways in which social processes allocate goods and burdens that impact health. Ultimately, we hope this synthesis of recent methodologic innovations in social epidemiology will enhance and inspire new efforts to improve the health of populations.

\section{Compliance with Ethics Guidelines}

Conflict of Interest J.M. Oakes declares no conflicts of interest.

K.N. Andrade declares no conflicts of interest.

Human and Animal Rights and Informed Consent All studies by J.M. Oakes involving animal and/or human subjects were performed after approval by the appropriate institutional review boards. When required, written informed consent was obtained from all participants.

\section{References}

Papers of particular interest, published recently, have been highlighted as:

- Of importance

1. Galea S, Link BG. Six paths for the future of social epidemiology. Am J Epidemiol. 2013;178(6):843-9.

2. Kawachi I. Editorial: Isn't all epidemiology social? Am J Epidemiol. 2013;178(6):841-2.
3. Oakes JM. Invited commentary: paths and pathologies of social epidemiology. Am J Epidemiol. 2013;178(6):850-1.

4. Oakes JM, Kaufman JS. Methods in social epidemiology. San Francisco: Jossey-Bass / Wiley; 2006.

5. Kaufman JS. Some models just can't be fixed. A commentary on Mortensen. Soc Sci Med. 2013;76(1):8-11.

6. Oakes JM. Causal inference and the relevance of social epidemiology. Soc Sci Med. 2004;58(10):1969-71.

7. Ahern J, Hubbard A, Galea S. Estimating the effects of potential public health interventions on population disease burden: a stepby-step illustration of causal inference methods. Am J Epidemiol. 2009;169(9):1140-7.

8. Glass TA, McAtee MJ. Behavioral science at the crossroads in public health: extending horizons, envisioning the future. Soc Sci Med. 2006;62(7):1650-71.

9. Glass TA, Goodman SN, Hernán MA, et al. Causal inference in public health. Annu Rev Public Health. 2013;34:61-75.

10. Kaufman JS, Cooper RS. Seeking causal explanations in social epidemiology. Am J Epidemiol. 1999;150(2):113-20.

11. Harper S, Strumpf EC. Commentary: social epidemiology: questionable answers and answerable questions. Epidemiology. 2012;23(6):795-8. This paper explains why some important questions in social epidemiology cannot be answered.

12. Hernan MA. A definition of causal effect for epidemiological research. J Epidemiol Community Health. 2004;58(4):265-71.

13. Morgan SL, Winship C. Counterfactuals and causal inference: methods and principles for social research. New York: Cambridge University Press; 2007.

14. Pearl J. Causality: models, reasoning, and inference. New York: Cambridge University Press; 2000.

15. Angrist JD, Pischke J-S. Mostly harmless econometrics: an empiricist's companion. Princeton: Princeton University Press; 2008.

16. Oakes M. Effect identification in comparative effectiveness research. eGEMs (Generating Evidence \& Methods to improve patient outcomes). 2013;1(1):4. doi:10.13063/2327-9214.1004.

17. Bingenheimer JB. Multilevel models and scientific progress in social epidemiology. J Epidemiol Community Health. 2005;59(6): 438-9.

18. Diez Roux AV. Next steps in understanding the multilevel determinants of health. J Epidemiol Community Health. 2008;62(11): 957-9.

19. Oakes JM. Invited commentary: rescuing Robinson Crusoe. Am J Epidemiol. 2008;168(1):9-12.

20. Berk RA, Rossi PH. Thinking about program evaluation. Thousand Oaks: Sage; 1999.

21. King G, Zeng L. The dangers of extreme counterfactuals. Polit Anal. 2006;14(2):131-59.

22. Galea S. An argument for a consequentialist epidemiology. Am J Epidemiol. 2013;178(8):1185-91.

23. Lynch JW, Law C, Brinkman S, et al. Inequalities in child healthy development: some challenges for effective implementation. Soc Sci Med. 2010;71(7):1244-8. discussion 54-8.

24. Diez Roux AV. Conceptual approaches to the study of health disparities. Annu Rev Public Health. 2012;33:41-58.

25. Frohlich KL, Potvin L. Commentary: structure or agency? The importance of both for addressing social inequalities in health. Int J Epidemiol. 2010;39(2):378-9.

26. Kaufman JS, Harper S. Health equity: utopian and scientific. Prev Med. 2013;57(6):739-40. This paper explains why rigorous methods are necessary to understand and remedy health disparities.

27. Hannan PJ. Experimental social epidemiology: controlled community trials. In: Oakes JM, Kaufman JS, editors. Methods in social epidemiology. San Francisco: Jossey-Bass / Wiley; 2006. p. 335-64. 
28. Wagenaar AC, Murray DM, Gehan JP, et al. Communities mobilizing for change on alcohol: outcomes from a randomized community trial. J Stud Alcohol. 2000;61(1):85-94.

29. Biglan A, Ary D, Wagenaar AC. The value of interrupted timeseries experiments for community intervention research. Prev Sci. 2000;1(1):31-49.

30. Oakes JM. Commentary: advancing neighbourhood-effects research-selection, inferential support, and structural confounding. Int J Epidemiol. 2006;35(3):643-7.

31. Oakes JM, Johnson PJ. Propensity score matching methods for social epidemiology. In: Oakes JM, Kaufman JS, editors. Methods in social epidemiology. San Francisco: Jossey-Bass; 2006. p. 370-92.

32. Messer LC, Oakes JM, Mason S. Effects of socioeconomic and racial residential segregation on preterm birth: a cautionary tale of structural confounding. Am J Epidemiol. 2010;171(6):664-73.

33. Oakes JM, Messer LC, Messer MS, et al. Respond to "positivity in practice". Am J Epidemiol. 2010. doi:10.1093/aje/kwp439.

34. Oakes JM, Forsyth A, Schmitz KH. The effects of neighborhood density and street connectivity on walking behavior: the Twin Cities walking study. Epidemiol Perspect Innov. 2007;4:16.

35. Leal C, Bean K, Thomas F, et al. Are associations between neighborhood socioeconomic characteristics and body mass index or waist circumference based on model extrapolations? Epidemiology. 2011;22(5):694-703.

36. Ahern J, Galea S. Collective efficacy and major depression in urban neighborhoods. Am J Epidemiol. 2011;173(12):1453-62.

37. Ho DE, Imai K, King G, et al. Matching as nonparametric preprocessing for reducing model dependence in parametric causal inference. Polit Anal. 2007;15(3):199-236.

38. Cerda M, Morenoff JD, Hansen BB, et al. Reducing violence by transforming neighborhoods: a natural experiment in Medellin, Colombia. Am J Epidemiol. 2012;175(10):1045-53.

39. Bruckner TA, Brown RA, Margerison-Zilko C. Positive income shocks and accidental deaths among Cherokee Indians: a natural experiment. Int J Epidemiol. 2011;40(4):1083-90.

40. Branas CC, Cheney RA, MacDonald JM, et al. A difference-indifferences analysis of health, safety, and greening vacant urban space. Am J Epidemiol. 2011;174(11):1296-306.

41. Glymour MM. Natural experiments and instrumental variable analyses in social epidemiology. In: Oakes JM, Kaufman JS, editors. Methods in social epidemiology. San Francisco: JosseyBass / Wiley; 2006. p. 423-45.

42. Glymour MM, Tchetgen EJT, Robins JM. Credible Mendelian randomization studies: approaches for evaluating the instrumental variable assumptions. Am J Epidemiol. 2012;175(4):332-9. This paper illuminates the necessary assumptions required for the credible use of instrumental variable methods.

43. Sampson RJ. Collective efficacy theory: lessons learned and directions for future inquiry. Taking Stock Status Criminol Theory. 2008; 15:149.

44. Muennig P, Cohen AK, Palmer A, et al. The relationship between five different measures of structural social capital, medical examination outcomes, and mortality. Soc Sci Med. 2013;85:18-26.

45. Giordano GN, Bjork J, Lindstrom M. Social capital and self-rated health-a study of temporal (causal) relationships. Soc Sci Med. 2012;75(2):340-8

46. Fletcher $\mathrm{J}$. The effects of intimate partner violence on health in young adulthood in the United States. Soc Sci Med. 2010;70(1): $130-5$.

47. Karlsen S, Nazroo J. Measuring and analyzing "race," racism, and racial discrimination. In: Oakes JM, Kaufman JD, editors. Methods in social epidemiology. San Francisco: Jossey-Bass/ Wiley; 2006. p. 86-111.

48. Kaufman JS, Cooper RS. The use of racial/ethnic categories in medical diagnosis and treatment. In: Whitmarsh I, Jones DS, editors. What's the use of race? Modern governance and the biology of difference. Cambridge: The MIT Press; 2010. p. 187-206.

49. Cooper RS. Race in biological and biomedical research. Cold Spring Harb Perspect Med. 2013;3:1-10.

50. Lewis TT, Yang FM, Jacobs EA, et al. Racial/ethnic differences in responses to the everyday discrimination scale: a differential item functioning analysis. Am J Epidemiol. 2012;175(5):391-401.

51. Messer LC, Kaufman JS. Invited commentary: the socioeconomic causes of adverse birth outcomes. Am J Epidemiol. 2010;172(2): 135-7. discussion 8-9.

52. Das A. How does race get "under the skin"?: inflammation, weathering, and metabolic problems in late life. Soc Sci Med. 2013;77:75-83.

53. Ford CL, Airhihenbuwa CO. The public health critical race methodology: praxis for antiracism research. Soc Sci Med. 2010;71(8): 1390-8.

54. Ford CL, Harawa NT. A new conceptualization of ethnicity for social epidemiologic and health equity research. Soc Sci Med. 2010;71(2):251-8.

55. Oakes JM, Rossi PH. The measurement of SES in health research: current practice and steps toward a new approach. Soc Sci Med. 2003;56(4):769-84.

56. Oakes JM. The Measurement of SES. Textbook Research Methods for Health Research, 2012. National Institutes of Health (NIH): Office of Behavioral \& Social Sciences Research. Available at: http://www.esourceresearch.org/. This chapter argues that the term SES should no longer be used in scientific discourse.

57. Hajat A, Kaufman JS, Rose KM, et al. Long-term effects of wealth on mortality and self-rated health status. Am J Epidemiol. 2011;173(2):192-200.

58. Nieto FJ. Commentary: understanding the pathophysiology of poverty. Int J Epidemiol. 2009;38(3):787-90.

59. Howe LD, Galobardes B, Matijasevich A, et al. Measuring socioeconomic position for epidemiological studies in low- and middleincome countries: a methods of measurement in epidemiology paper. Int J Epidemiol. 2012;41(3):871-86.

60. Subramanian S, Corsi DJ, Subramanyam MA, et al. Jumping the gun: the problematic discourse on socioeconomic status and cardiovascular health in India. Int J Epidemiol. 2013;42(5):1410-26.

61. Chen JT, Beckfield J, Waterman PD, et al. Can changes in the distributions of and associations between education and income bias temporal comparisons of health disparities? An exploration with causal graphs and simulations. Am J Epidemiol. 2013. doi: 10.1093/aje/kwt041

62. Harper S, Lynch J. Measuring health inequalities. In: Oakes J, Kaufman J, editors. Methods in social epidemiology. San Francisco: Jossey-Bass; 2006. p. 134-68.

63. Krieger N. Embodying inequality: a review of concepts, measures, and methods for studying health consequences of discrimination. Int J Health Serv. 1999;29(2):295-352.

64. Reardon SF. A conceptual framework for measuring segregation and its association with population outcomes. In: Oakes JM, Kaufman JS, editors. Methods in social epidemiology. San Francisco: Jossey-Bass / Wiley; 2006. p. 169-92.

65. Osypuk T, Bates LM, Acevedo-Garcia D. Another Mexican birthweight paradox? The role of residential enclaves and neighborhood poverty in the birthweight of Mexican-origin infants. Soc Sci Med. 2010;70:550-60.

66. Hearst MO, Oakes JM, Johnson PJ. The effect of racial residential segregation on black infant mortality. Am J Epidemiol. 2008;168(11):1247-54.

67. Kershaw KN, Albrecht SS, Carnethon MR. Racial and ethnic residential segregation, the neighborhood socioeconomic environment, and obesity among Blacks and Mexican Americans. Am J Epidemiol. 2013;177(4):299-309. 
68. Christakis NA, Fowler JH. The spread of obesity in a large social network over 32 years. N Engl J Med. 2007;357(4):370-9.

69. Celentano DD. Social networks and health: models, methods, and applications: by Thomas W. Valente. Am J Epidemiol. 2010;172(4):488.

70. Doherty IA, Serre ML, Gesink D, et al. Sexual networks, surveillance, and geographical space during syphilis outbreaks in Rural North Carolina. Epidemiology. 2012;23(6):845-51.

71. Fujimoto K, Valente TW. Social network influences on adolescent substance use: disentangling structural equivalence from cohesion. Soc Sci Med. 2012;74(12):1952-60.

72. Homer JB, Hirsch GB. System dynamics modeling for public health: background and opportunities. Am J Public Health. 2006;96(3):452-8.

73. Koopman JS, Lynch JW. Individual causal models and population system models in epidemiology. Am J Public Health. 1999;89(8): $1170-4$.

74. El-Sayed AM, Seemann L, Scarborough P, et al. Are networkbased interventions a useful antiobesity strategy? An application of simulation models for causal inference in epidemiology. Am J Epidemiol. 2013;178(2):287-95.

75. Galea S, Riddle M, Kaplan GA. Causal thinking and complex system approaches in epidemiology. Int J Epidemiol. 2010;39(1): 97-106.

76. Auchincloss AH, Roux AVD. A new tool for epidemiology: the usefulness of dynamic-agent models in understanding place effects on health. Am J Epidemiol. 2008;168(1):1-8.

77. Yang Y, Diez Roux AV, Auchincloss AH, et al. A spatial agentbased model for the simulation of adults' daily walking within a city. Am J Prevent Med. 2011;40(3):353-61.

78. Roux AVD. Complex systems thinking and current impasses in health disparities research. Am J Public Health. 2011;101(9):1627.

79. Gatrell AC. Complexity theory and geographies of health: a critical assessment. Soc Sci Med. 2005;60(12):2661-71.

80. Bengtsson T, Mineau GP. Introduction. Early-life effects on socioeconomic performance and mortality in later life: a full life-course approach using contemporary and historical sources. Soc Sci Med. 2009;68:1561-4.

81. la Bastide-van Gemert S, Stolk RP, van den Heuvel ER, et al. Causal inference algorithms can be useful in life course epidemiology. J Clin Epidemiol. 2013;67(2):190-8.

82. Davey SG. Is the first cut the deepest? Ernst Engel on the statistical imperative of embracing the lifecourse perspective. Int $\mathrm{J}$ Epidemiol. 2011;40(5):1135-7.

83. Davey SG. Intergenerational influences on health: how far back do we have to go? Int J Epidemiol. 2009;38(3):617-8.

84. Kawachi I, Berkman LF, editors. Neighborhoods and health. New York: Oxford; 2002.

85. Oakes JM. The (mis)estimation of neighborhood effects: causal inference for a practicable social epidemiology. Soc Sci Med. 2004;58(10):1929-52.

86. Vanderweele TJ. Ignorability and stability assumptions in neighborhood effects research. Stat Med. 2008;27(11):1934-43.

87. Schaefer-McDaniel N, Dunn JR, Minian N, et al. Rethinking measurement of neighborhood in the context of health research. Soc Sci Med. 2010;71(4):651-6.
88. Bab C, Cab L, Dabc E. Neighborhood-level confounding in epidemiologic studies: unavoidable challenges, uncertain solutions. Epidemiology. 2010;21(1):124-7.

89. Bab C, Nab B, Fc T, et al. Neighborhood effects on health: correcting bias from neighborhood effects on participation. Epidemiology. 2011;22(1):18-26.

90. Sariaslan A, Langstrom N, D'Onofrio B, et al. The impact of neighbourhood deprivation on adolescent violent criminality and substance misuse: a longitudinal, quasi-experimental study of the total Swedish population. Int J Epidemiol. 2013;42(4):1057-66.

91. Oakes JM. Commentary: identification, neighbourhoods and families. Int J Epidemiol. 2013;42(4):1067-9.

92. Merlo J, Ohlsson H, Chaix B, et al. Revisiting causal neighborhood effects on individual ischemic heart disease risk: a quasiexperimental multilevel analysis among Swedish siblings. Soc Sci Med. 2013;76(1):39-46.

93. Votruba ME, Kling JR. Effects of neighbourhood characteristics on the mortality of black male youth: evidence from Gatreaux, Chicago. Soc Sci Med. 2009;68:814-23.

94. Robins JM, Greenland S. Identifiability and exchangeability for direct and indirect effects. Epidemiology. 1992;3(2):143-55.

95. Kaufman JS, MacLehose RF, Kaufman S. A further critique of the analytic strategy of adjusting for covariates to identify biologic mediation. Epidemiol Perspect Innov. 2004;1(1):4.

96. VanderWeele TJ. Direct and indirect effects for neighborhoodbased clustered and longitudinal data. Sociol Methods Res. 2010;38(4):515-44.

97. Nandi A, Glymour MM, Kawachi I, et al. Using marginal structural models to estimate the direct effect of adverse childhood social conditions on onset of heart disease, diabetes, and stroke. Epidemiol (Cambridge, Mass). 2012;23(2):223.

98. Baron RM, Kenny DA. The moderator-mediator variable distinction in social psychological research: conceptual, strategic, and statistical considerations. J Pers Soc Psych. 1986;51(6):1173.

99. Freese J, Shostak S. Genetics and social inquiry. Annu Rev Sociol. 2009;35:107-28.

100. Rehkopf DH, Adler N. Commentary: it's not all means and genessocio-economic position, variation and genetic confounding. Int $\mathrm{J}$ Epidemiol. 2010;39(2):415-6.

101. Toyokawa S, Uddin M, Koenen KC, et al. How does the social environment 'get into the mind'? Epigenetics at the intersection of social and psychiatric epidemiology. Soc Sci Med. 2012;74(1): $67-74$.

102. Gottfredson LS. Intelligence: is it the epidemiologists' elusive" fundamental cause" of social class inequalities in health? J Pers Soc Psych. 2004;86(1):174.

103. VanderWeele TJ, Hawkley LC, Cacioppo JT. On the reciprocal association between loneliness and subjective well-being. Am J Epidemiol. 2012;176(9):777-84.

104. Gintis H. The hitchhiker's guide to altruism: gene-culture coevolution, and the internalization of norms. J Theor Biol. 2003;220(4): 407-18.

105. Glass TA. Commentary: culture in epidemiology - the 800 pound gorilla? Int J Epidemiol. 2006;35(2):259-61.

106. Elster J. Local justice: How institutions allocate scarce goods and necessary burdens. New York: Russell Sage; 1992. 